Article

\title{
Applying Baghdadite/PCL/Chitosan Nanocomposite Coating on AZ91 Magnesium Alloy to Improve Corrosion Behavior, Bioactivity, and Biodegradability
}

\author{
Farzad Soleymani ${ }^{1}$, Rahmatollah Emadi ${ }^{2}$, Sorour Sadeghzade ${ }^{2,3}$ and Fariborz Tavangarian ${ }^{3, *}$ \\ 1 Materials Engineering Group, Pardis College, Isfahan University of Technology, Isfahan 84156-83111, Iran; \\ fsoleimani236@gmail.com \\ 2 Materials Research Group, Department of Materials Engineering, Isfahan University of Technology, \\ Isfahan 84156-83111, Iran; remadi@cc.iut.ac.ir (R.E.); soroursadeghzade@gmail.com (S.S.) \\ 3 Mechanical Engineering Program, School of Science, Engineering and Technology, Pennsylvania State \\ University, Harrisburg, Middletown, PA 17057, USA \\ * Correspondence: f_tavangarian@yahoo.com; Tel.: +1-717-948-6125
}

Received: 5 November 2019; Accepted: 20 November 2019; Published: 25 November 2019

\begin{abstract}
Magnesium alloys have received a great amount of attention regarding being used in biomedical applications; however, they show high degradability, poor bioactivity, and biocompatibility. To improve these properties, surface modification and various types of coatings have been applied. In this study, an anodized AZ91 alloy was coated with a polymer matrix composite made of polycaprolactone/chitosan (PCL/Ch) with different percentages of baghdadite to improve its resistance to corrosion, bioactivity, and biocompatibility. The effects of different percentages of baghdadite $(0 \mathrm{wt} \%, 1 \mathrm{wt} \%, 3 \mathrm{wt} \%$, and $5 \mathrm{wt} \%$ ) on the surface microstructure, corrosion resistance, roughness, and wettability were evaluated. The results indicated that the applied nano-polymer-ceramic coating including $3 \mathrm{wt} \%$ baghdadite was hydrophobic, which consequently increased the corrosion resistance and decreased the corrosion current density of the anodized AZ91 alloy. Coating with $3 \mathrm{wt} \%$ baghdadite increased the roughness of AZ91 from $0.329 \pm 0.02$ to $7.026 \pm 0.31 \mu \mathrm{m}$. After applying the polymer-ceramic coating on the surface of anodized AZ91, the corrosion products changed into calcium-phosphate compounds instead of $\mathrm{Mg}(\mathrm{OH})_{2}$, which is more stable in a physiological environment.
\end{abstract}

Keywords: polycaprolactone; coating; Mg alloy; chitosan; baghdadite

\section{Introduction}

Some metals have been used as implants for biomedical applications due to their suitable properties [1,2]. Most of the metals used in vivo are bioinert and have a high stability as well as low degradation rate $[3,4]$. These, in turn, lead to the emergence of some problems such as the stress shielding phenomenon, failure to stimulate the surrounding tissue to grow, release of metal ions into the environment, and inflammation in the body $[4,5]$. In the meantime, since metal implants are heavy [6-8], medical science has progressed towards using lightweight materials with a controllable degradation rate to allow tissue ingrowth [7]. Magnesium alloys have recently attracted the attention of many scientists due to their high strength-to-weight ratio and degradability $[8,9]$. Magnesium is one of the most important and essential elements in living organisms, which indirectly affects the mineral metabolism $[10,11]$. In addition, stress shielding phenomenon does not occur for magnesium alloys due to having density and Young's modulus close to that of natural bone. The density of magnesium alloys is between 1.7 and $2.0 \mathrm{~g} / \mathrm{cm}^{3}$, which is very close to that of bone $\left(1.8-2.1 \mathrm{~g} / \mathrm{cm}^{3}\right)$ [12]. Also, the Young's moduli of magnesium and natural bone are $45 \mathrm{GPa}$ and 10-30 GPa, respectively [13]. 
Although the degradability of magnesium makes it an interesting material for biomedical applications, if not controlled, it will result in implant rejection and/or in worst cases, in the death of patients [14,15]. Therefore, it is crucial to control the corrosion of magnesium alloys to establish a balance between the degradability of the alloy and the growth of the new tissues $[16,17]$. Another common problem of magnesium implant is their low bioactivity [17]. Different methods such as alloying, surface treatment, and applying surface coatings are utilized to control the corrosion rate of magnesium and to improve its bioactivity and biocompatibility. Due to the high cost associated with the alloying process, surface treatment and coating methods have received more attention $[18,19]$. Different types of polymer, ceramic, and composite coatings have been applied in order to enhance the corrosion resistance, bioactivity, and biocompatibility of magnesium alloys [19]. Among these coatings, polymer coatings provide a higher corrosion resistance compare to ceramic coatings, as they form a layer without any porosities and/or cracks [20-22]. One of the polymers that attracted the attention of scientists is polycaprolactone (PCL) due to its high mechanical properties as well as its stability in vivo [23,24]. However, this synthetic polymer has low hydrophobicity and cell affinity, which adversely affect its bonding to surrounding tissue [25]. To address this problem, composites of PCL with bioactive ceramics have been developed to improve cell adhesion and bonding to surrounding tissue. Baghdadite is a calcium zirconium silicate with the chemical formula od $\mathrm{Ca}_{3} \mathrm{ZrSi}_{2} \mathrm{O}_{9}$. Baghdadite shows superior bioactivity, biodegradability, cell attachment, and proliferation compared to conventional calcium phosphate ceramics such as hydroxyapatite and $\beta$-tricalcium phosphate [26-30]. The presence of calcium and zirconium ions in this ceramic increases the mineral metabolism and ossification [30]. Several studies have reported the application of baghdadite ceramic in tissue engineering fields. Sadeghzade et al. [30] prepared pure baghdadite scaffolds under various temperature $\left(1250-1350{ }^{\circ} \mathrm{C}\right)$. The optimum mechanical and physical properties were achieved in $1350^{\circ} \mathrm{C}$ under $65 \mathrm{MPa}$ compression pressure and $80 \mathrm{wt} \% \mathrm{NaCl}$ with a spherical morphology. The scaffolds showed a high bioactivity and biocompatibility compared to hydroxyapatite scaffolds. In other studies, they reported [31,32] a high BMSC cell attachment, proliferation rate, and cell spreading on diopside/baghdadite scaffolds. Roohani-Esfahani et al. [33] reported an extensive new bone formation in radial defect using baghdadite scaffolds, which was not observed in the $\beta$-tricalcium phosphate/hydroxyapatite scaffolds as control samples. On the other hand, adding natural polymers such as chitosan can improve biocompatibility due to their closer structure to that of body tissues [34,35].

The aim of this study was to apply a polymer-ceramic composite coating to a magnesium alloy (AZ91) to improve its corrosion resistance and bioactivity. Different composites of polycaprolactonechitosan-baghdadite were evaluated in this study. The wettability and roughness of the applied coatings on the surface of AZ91 and their effects on the bio-behavior of the composite were evaluated. Furthermore, the corrosion behavior of the coated magnesium alloy as well as its corrosion mechanism were investigated. The results showed that applying the polymer-ceramic composite coating can be an effective method to control the degradation and bioactivity of the magnesium alloys for tissue engineering applications.

\section{Materials and Methods}

\subsection{Sample Preparation}

In this study, AZ91 magnesium alloy was cut to rectangular samples with the dimension of $2 \times$ $10 \times 10 \mathrm{~mm}^{3}$. The chemical composition of AZ91 ingot is provided in Table 1. Before applying the coating, the samples were sanded with 80-2400 grits SiC sandpapers and then were polished with $\mathrm{Al}_{2} \mathrm{O}_{3}$ powder. Finally, the samples were cleaned ultrasonically in an acetone solution for $20 \mathrm{~min}$ and then dried in air. 
Table 1. Chemical composition of AZ91 magnesium alloy (wt \%) ingot.

\begin{tabular}{ccccc}
\hline Elements & Al & Zn & Mn & Mg \\
\hline wt $\%$ & 8.65 & 0.6 & 0.17 & Balanced \\
\hline
\end{tabular}

\subsection{Micro-Arc oxidation (MAO) Coating Process}

In order to prepare the electrolyte of MAO process, $100 \mathrm{~g}$ of $\mathrm{NaOH}$ and $100 \mathrm{~g}$ of $\mathrm{Na}_{2} \mathrm{SiO}_{3}$ were mixed in $1 \mathrm{~L}$ of distilled water [36]. Samples of an AZ91 magnesium alloy and a stainless-steel plate were placed in the solution as the anode and cathode, respectively. MAO was carried out at a voltage of $60 \mathrm{~V}$ for 30 minutes. Next, the samples were washed with distilled water, and then ultrasonically cleaned in an acetone solution. After that, they were again rinsed with distilled water and dried under the blowing of warm air.

\subsection{Preparation of Baghdadite Nanopowder}

The sol-gel method was used to produce baghdadite nanopowder [30]. In this method, zirconium oxynitrate, calcium nitrate, and tetraethyl orthosilicate (TEOS) (all from Sigma-Aldrich, St. Louis, MI, USA) were used as raw materials with a stoichiometric ratio of 1:3:2. First, TEOS, ethanol, and nitric acid, with a molar ratio of 1:8:0.16 were mixed together using a magnetic stirrer for 30 minutes. Then, the raw materials were added to the solution and the obtained slurry was stirred at room temperature for five hours. After that, the clear sol was dried at $60^{\circ} \mathrm{C}$ temperature for one day and then at $100{ }^{\circ} \mathrm{C}$ for two days. The dried gel was then calcined at $1150{ }^{\circ} \mathrm{C}$ for three hours followed by $2 \mathrm{~h}$ ball milling.

\subsection{Ceramic/Polymer Coating Preparation}

In order to create a polymer coating on the anodized samples of AZ91, $90 \mathrm{wt} \%$ of polycaprolactone (PCL) (with a molecular weight of 60,000, Sigma-Aldrich) and $10 \mathrm{wt} \%$ of Chitosan (Ch) (with a molecular weight of 50,000, Sigma-Aldrich) were dissolved in a mixture of acetic acid and formic acid with a weight ratio of 3 to 1 [35]. Next, different percentages of baghdadite nanopowder $(0 \mathrm{wt} \%$, $1 \mathrm{wt} \%, 3 \mathrm{wt} \%$, and $5 \mathrm{wt} \%$ ) were added to the polymer solutions and the solutions were stirred for $3 \mathrm{~h}$. Table 2 shows the designation of different samples. The coating operation was performed through the immersion method at the entry and exit speeds of $6 \mathrm{~mm} / \mathrm{min}$, and five times for each sample. The coated samples were dried in an air atmosphere for $48 \mathrm{~h}$.

Table 2. The designation of various samples.

\begin{tabular}{cc}
\hline Designation & Sample \\
\hline M & AZ91 \\
M1 & MAO \\
M2 & Baghdadite powder \\
M3 & MAO-PCL/Ch \\
M4 & MAO-PCL/Ch-1 wt \%Bagh \\
M5 & MAO-PCL/Ch-3 wt \%Bagh \\
M6 & MAO-PCL/Ch-5 wt \%Bagh \\
\hline
\end{tabular}

\subsection{Characterization of Modified and Unmodified Samples (Coated and Noncoated Samples)}

In order to investigate the corrosion behavior of different samples, electrochemical tests including a polarization corrosion test and electrochemical impedance spectroscopy (EIS) were carried out in a simulated body fluid (SBF) using a potentiostat (Model: PARATAT 2273, AMETEK, Oak Ridge, TN, USA). To this end, an electrochemical cell containing three electrodes with the following configuration was established: The samples were placed at the position of the working electrode, the platinum electrode at the position of the counter electrode, and the saturated calomel electrode (SCE) at the position of the reference electrode. All corrosion tests were performed after reaching a steady state 
within $60 \mathrm{~min}$. A potentiodynamic polarization test was performed at a scanning speed of $1 \mathrm{mV} / \mathrm{s}$, and the frequency range for the EIS test was chosen between $100 \mathrm{kHz}$ and $10 \mathrm{mHz}$. A wettability test was carried out using an angle finder in order to investigate the effect of baghdadite nanoparticles on the hydrophilic or hydrophobic behavior of the applied polymer coating on the AZ91 samples. In each of the tests, a droplet of $2 \mu \mathrm{L}$ was laid on the surface of the samples using a DragonLab StepMate stepper (Model: JV62782, DragonLab, Beijing, China). The average wettability angle was reported using Image software version 1.52q. In order to examine the surface roughness before and after coating, a Mitutoyo roughness meter (Model: SJ-210, Grainger, Chicago, IL, USA) was used, and the mean surface roughness $\left(R_{\mathrm{a}}\right)$ was reported. To ensure the accuracy of the results, all the tests were repeated three times. Phase analysis of different samples was performed using X-ray diffraction (XRD) technique by Philips (Modle:PW1730, Philips, Amsterdam, The Netherlands) with $\mathrm{Cu} K \alpha$ radiation with $\lambda=0.154 \mathrm{~nm}, 20 \mathrm{kV}$, and $30 \mathrm{~mA}$, in the $2 \theta$ range of $20^{\circ}-70^{\circ}$ (step size $0.05^{\circ}$ and time per step $1 \mathrm{~s}$ ). Scanning electron microscopy (SEM) (Philips XL30, acceleration voltage of $30 \mathrm{kV}$, Amsterdam, The Netherlands) and energy-dispersive spectroscope (EDS) (Philips XL30, Amsterdam, The Netherlands) were used to investigate the surface morphology and elemental analyses of the surface of modified and unmodified samples. The powder morphology and crystallite size were investigated by a transmission electron microscope (TEM) (TEM, Philips, EM208S, Amsterdam, The Netherlands) with the applied voltage of $100 \mathrm{kV}$. ImageJ software was used to measure the baghdadite crystallite size.

\section{Results and Discussions}

TEM micrograph of baghdadite powder fabricated by sol-gel method is shown in Figure 1. The baghdadite powder had crystals mostly with a spherical shape, which were highly agglomerated. The crystal size of baghdadite nanopowder was in the range of 20-70 nm.

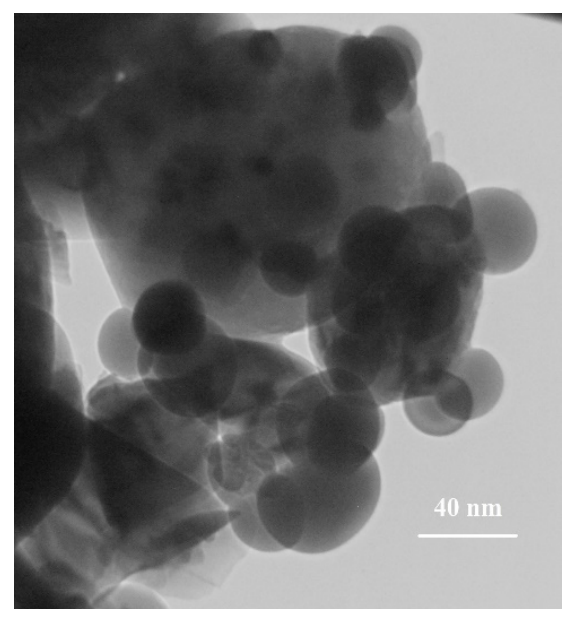

Figure 1. TEM micrograph of baghdadite nanopowder fabricated by sol-gel method.

Figure 2 shows the XRD patterns of AZ91, MAO samples, synthesized baghdadite powder, as well as the samples after polymer coating with different percentages of baghdadite nanopowder. The XRD pattern of AZ91 shows peaks corresponding to the magnesium phase (JCPDS: 00-004-0770). The XRD pattern of the AZ91 sample coated with MAO is in a good agreement with standard magnesium, magnesium oxide (JCPDS: 01-077-2364), and forsterite (JCPDS: 01-085-1364) reference cards. The XRD pattern of M2 sample in Figure 2 is according to the characteristic peaks of baghdadite (JCPDS 00-047-1854). The XRD pattern of the sample with a polymer coating (M3) showed the presence of PCL and chitosan peaks at $2 \theta$ angles of 21.6 and 23 degrees. The XRD patterns of specimens with different percentages of baghdadite (M4-M6) proved the presence of baghdadite phase in the coating. In addition, with increasing the percentage of baghdadite from 1 to $5 \mathrm{wt} . \%$ in the coating, the intensity of baghdadite peaks increased. 


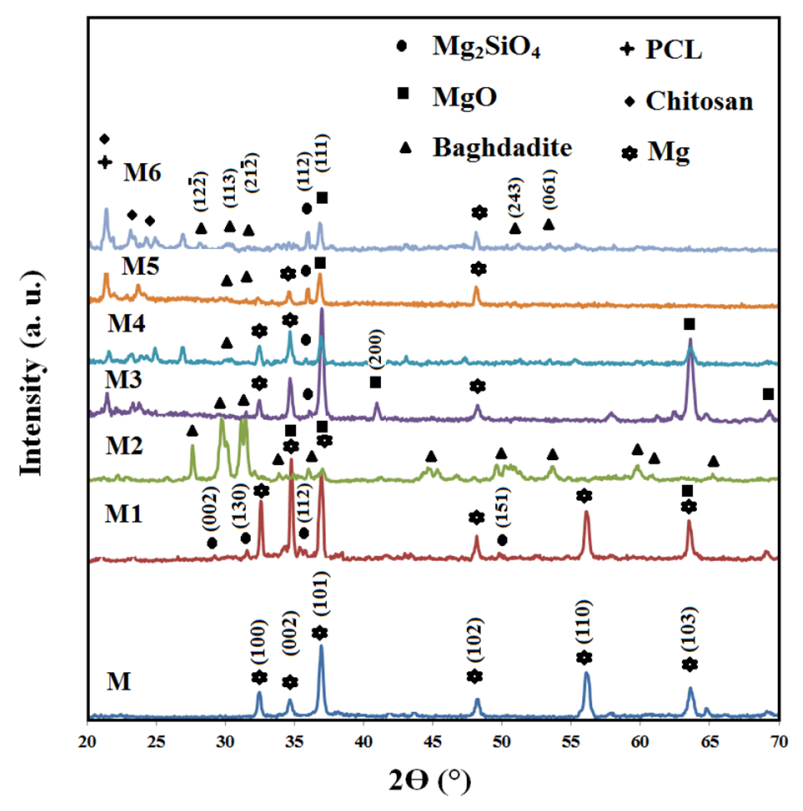

Figure 2. XRD patterns of various samples.

Figure 3 shows the SEM images of the surfaces of anodized sample (M1), and the samples after coating (M3-M6). The presence of a layer of $\mathrm{MgO}$ on the surface of AZ91 alloy, as well as the presence of dispersed forsterite particles (shown by arrows in Figure 3a,b) can act as a protective and intermediate layer for better adhesion of the coating to the substrate. The results obtained from the EDS analysis confirmed the formation of $\mathrm{MgO}$ and forsterite on the surface of sample (Figure 3j). The obtained results are in a good agreement with the studies conducted by other researchers on the anodized AZ91 alloy [37]. Besides increasing the corrosion resistance of AZ91 substrate, the presence of uneven porous layer on the surface improves the adhesion of the polymer coating to the substrate [38]. As can be seen in Figure 3c, applying the polymer coating formed a smooth and uniform layer on the surface. The addition of $1 \mathrm{wt} \%$ baghdadite nanoparticles roughed the surface of the specimens (Figure 3d,e). With increasing the percentage of baghdadite nanoparticles up to $5 \mathrm{wt} \%$, the surface roughness increased. The formation of baghdadite agglomerates can be seen on the surface of M4 sample (shown by arrows in Figure 3h,i). Nonetheless, no crack or hole was observed due to the addition of baghdadite nanoparticles.
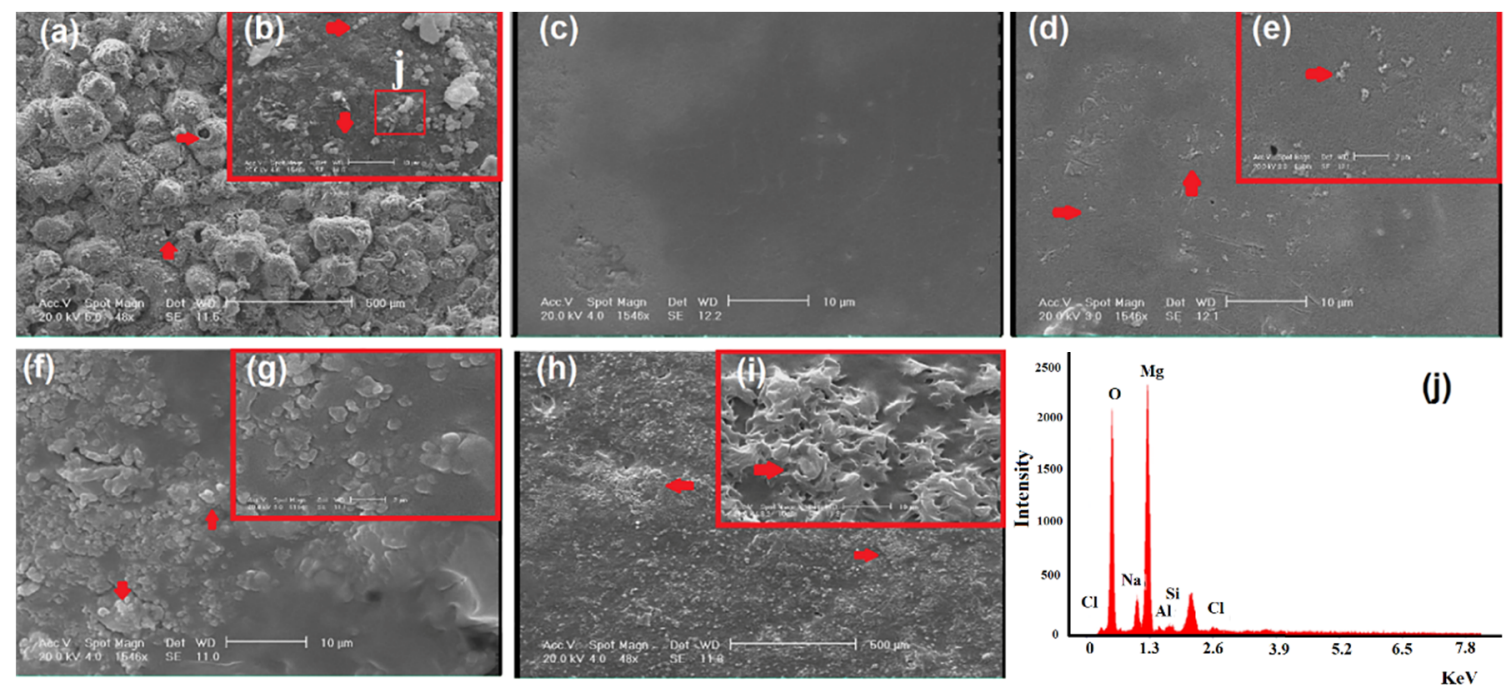

Figure 3. SEM images of (a,b) M1, (c) M3, (d,e) M4, (f, $\mathbf{g})$ M5, (h,i) M6, and (j) EDS result of insert in (b). 
Figure 4 shows a schematic illustration of forsterite and $\mathrm{MgO}$ formation in an MAO process. When magnesium is dissolved from the outer layer of the AZ91 substrate (due to its contact with the electrolyte solution and its reaction with the $\mathrm{O}^{2-}$ ion), an $\mathrm{MgO}$ layer is formed according to the following reaction [37]:

$$
\mathrm{Mg}^{2+}+\mathrm{O}^{2-} \rightarrow \mathrm{MgO}
$$

According to the literature, the presence of $\mathrm{SiO}_{3}{ }^{2-}$ in the electrolyte solution is due to the dissolution of $\mathrm{Na}_{2} \mathrm{SiO}_{3}$ in water, which occurs according to Reaction 2. It is converted into $\mathrm{Si}(\mathrm{OH})_{4}$ as a result of being hydrolyzed by water according to Reaction 3, and eventually converted into $\mathrm{SiO}_{2}$ as a result of applying a strong electric field and anodizing procedure at a high temperature (Reaction 4) [37,39]:

$$
\begin{aligned}
\mathrm{Na}_{2} \mathrm{SiO}_{3} & \rightarrow 2 \mathrm{Na}^{+}+\mathrm{SiO}_{3}^{2-} \\
4 \mathrm{H}_{2} \mathrm{O}+\mathrm{SiO}_{3}^{2-} & \rightarrow \mathrm{Si}(\mathrm{OH})_{4}+4(\mathrm{OH})^{-} \\
x \mathrm{Si}(\mathrm{OH})_{4} & \rightarrow x \mathrm{Si}_{2}+\mathrm{H}_{2} \mathrm{O}
\end{aligned}
$$

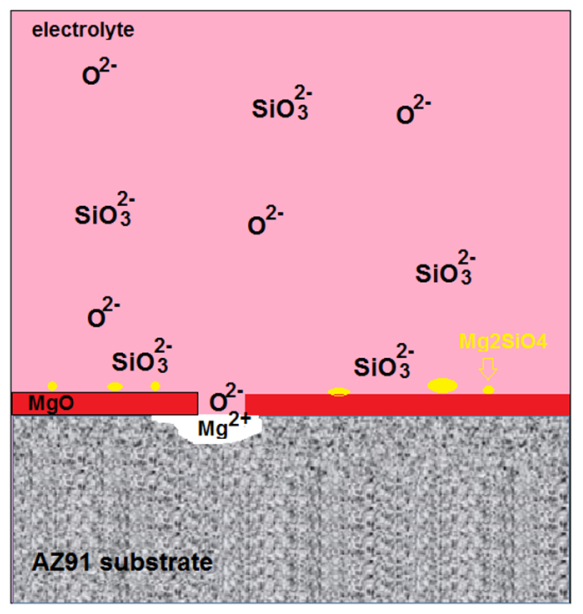

Figure 4. Schematic illustration of forsterite and $\mathrm{MgO}$ formation in a micro-arc oxidation (MAO) process.

During the process of plasma anodizing, $\mathrm{MgO}$ and $\mathrm{SiO}_{2}$ melt locally and are cooled in the aqueous medium of the electrolyte, which result in the formation of forsterite according to the following reaction $[17,37]$.

$$
2 \mathrm{MgO}+\mathrm{SiO}_{2} \rightarrow \mathrm{Mg}_{2} \mathrm{SiO}_{4}
$$

The results obtained from the roughness test (Table 3) suggested that the anodizing operation on the substrate increased the surface roughness from $0.329 \pm 0.02 \mu \mathrm{m}$ to $11.356 \pm 0.45 \mu \mathrm{m}$. The formation of polymer coating reduced the surface roughness down to $4.743 \pm 0.23 \mu \mathrm{m}$, whereas the addition of baghdadite nanoparticles ( $1 \mathrm{wt} \%$ to $5 \mathrm{wt} \%$ ) to the coating increased the surface roughness from $4.743 \pm 0.23 \mu \mathrm{m}(\mathrm{M} 3)$ to $7.792 \pm 0.34 \mu \mathrm{m}(\mathrm{M} 4), 7.026 \pm 0.31 \mu \mathrm{m}$ (M5), and $10.610 \pm 0.21 \mu \mathrm{m}(\mathrm{M} 6)$. One of the important benefits of applying a coating on the metal implants, is to facilitate the ingrowth and penetration of surrounding tissue into the coating and subsequently provide appropriate bonds between the implant and the surrounding tissue. This will be possible if an appropriate surface roughness is developed on the surface so that the tissue can adhere to the coating [38]. As can be seen, applying the polymer coating reduced the surface roughness, whereas addition of baghdadite nanoparticles increased the surface roughness, and created an uneven and porous surface, which will be appropriate for biostability, initial adhesion, and the growth of tissue. 
Table 3. The average surface roughness and wettability of modified and unmodified samples (average \pm standard deviation).

\begin{tabular}{ccc}
\hline Samples & Contact Angle $\left(^{\circ}\right)$ & Roughness $(\mu \mathrm{m})$ \\
\hline M & $1 \pm 86$ & $0.329 \pm 0.02$ \\
M1 & $33 \pm 1.3$ & $11.356 \pm 0.45$ \\
M3 & $51 \pm 2$ & $4.743 \pm 0.23$ \\
M4 & $59 \pm 1$ & $7.792 \pm 0.34$ \\
M5 & $72 \pm 1.2$ & $7.026 \pm 0.31$ \\
M6 & $66 \pm 1.3$ & $10.610 \pm 0.21$ \\
\hline
\end{tabular}

A water contact angle test was used in order to examine the hydrophobicity or hydrophilicity of the applied coatings on the anodized AZ91 alloy. The results showed that applying the polymer coating to the anodized AZ91 alloy reduced the wettability angle from $86^{\circ} \pm 1^{\circ}$ to $33^{\circ} \pm 1.3^{\circ}$, whereas adding baghdadite nanoparticles increased the wettability angle to $66^{\circ} \pm 1.3^{\circ}$ in the presence of $5 \mathrm{wt} \%$ baghdadite (Figure 5 and Table 3). Considering the fact that wetting angles between $0^{\circ}$ to $90^{\circ}$ show a hydrophilic surface [25], it can be concluded that all the specimens have a hydrophilic surface. Although the addition of baghdadite nanoparticles increased the wetting angle, the coating maintained its hydrophilic state in all samples.
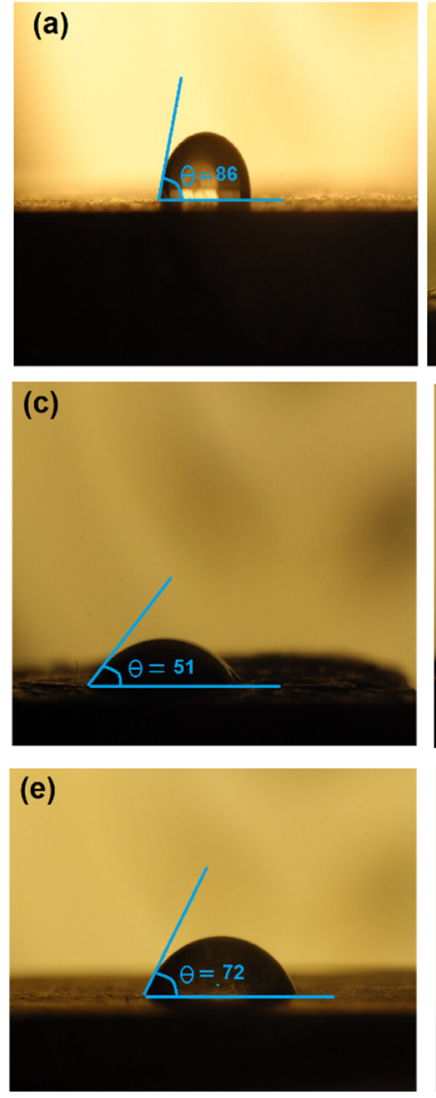
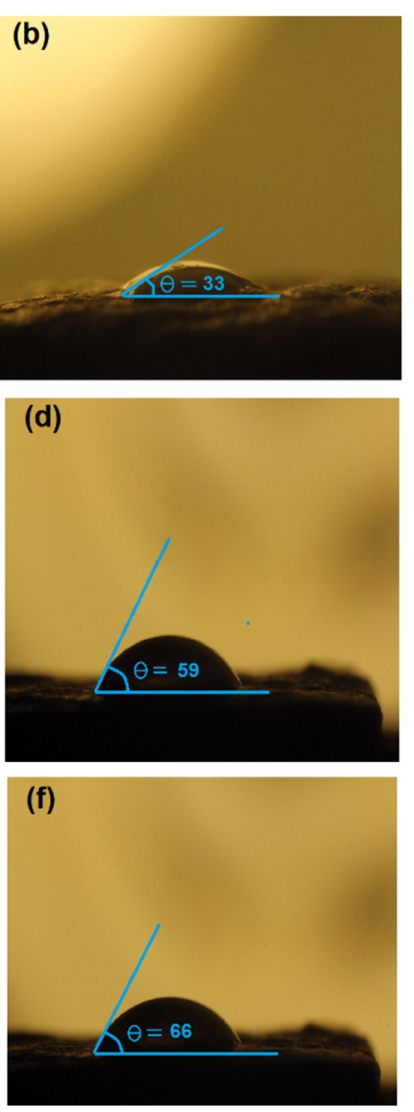

Figure 5. Optical microscopic images of water contact angle on the surface of modified and unmodified samples (a) M, (b) M1, (c) M3, (d) M4, (e) M5, and (f) M6.

A potentio-dynamic polarization test and electrochemical impedance spectroscopy (EIS) were carried out in a simulated body fluid (SBF, $\mathrm{pH}=7.4)$ in order to examine the corrosion rate and corrosion resistance of the specimens. The potentio-dynamic polarization curves in Figure 6 were used to evaluate the corrosion rate of the specimens before and after first and second coating. In general, lower corrosion current density shows higher corrosion potential and greater corrosion resistance. 
From Figure 6 and the results in Table 4 ( $I_{\text {corr }}$ (corrosion current density), $E_{\text {corr }}$ (corrosion voltage)), it can be seen that the corrosion current density for the uncoated AZ91 sample was $2 \times 10^{-4}(\mathrm{M})$, which decreased to $0.5 \times 10^{-6}$ due to the performing of the anodizing process (M1). Applying the polymer coating and adding baghdadite nanoparticles to the coating up to $3 \mathrm{wt} \%$ caused the decreasing trend to be continued, but with increasing the percentage of baghdadite to $5 \mathrm{wt} \%, I_{\text {corr }}$ increased, which can be attributed to the increased surface roughness $(10.61 \pm 0.23 \mu \mathrm{m})$ and hydrophilicity $\left(66^{\circ} \pm 1.3^{\circ}\right)$ of the coating. In addition, the corrosion potential for the AZ91 is equal to $-1.71 \mathrm{~V}$, whereas by performing MAO process and applying the baghdadite/polymer composite coating up to $3 \mathrm{wt} \%$ baghdadite, an upward trend was observed in the corrosion potential. On the other hand, adding more baghdadite to the coating (up to $5 \mathrm{wt} \%$ ) decreased the corrosion potential. According to the results of the potentio-dynamic polarization test, it can be concluded that the addition of baghdadite nanoparticles to the coating decreased the formation of cracks in the coating. As a result, an improvement was detected in the corrosion resistance of these specimens compared to that of the uncoated AZ91 sample. Furthermore, M5 specimen exhibited the best corrosion resistance among the coated specimens. The results of some studies on a pure magnesium alloy with a PCL/PLA polymer coating demonstrated a 10-fold decrease in the corrosion rate of the magnesium alloy in an SBF solution, whereas in the present study, we observed a 104-fold decrease by applying a ceramic/polymer composite coating [40].

Table 4. Electrochemical corrosion parameters derived from potentio-dynamic polarization experiments for modified and unmodified samples.

\begin{tabular}{ccc}
\hline Samples & $\boldsymbol{I}_{\text {corr }}\left(\mathbf{A} / \mathbf{c m}^{2}\right)$ & $\boldsymbol{E}_{\text {corr }}(\mathrm{V})$ \\
\hline M & $2 \times 10^{-4}$ & -1.71 \\
M1 & $0.5 \times 10^{-6}$ & -1.48 \\
M3 & $9.5 \times 10^{-7}$ & -1.43 \\
M4 & $4.2 \times 10^{-7}$ & -1.3 \\
M5 & $5.4 \times 10^{-8}$ & -1.15 \\
M6 & $9.4 \times 10^{-8}$ & -1.22 \\
\hline
\end{tabular}

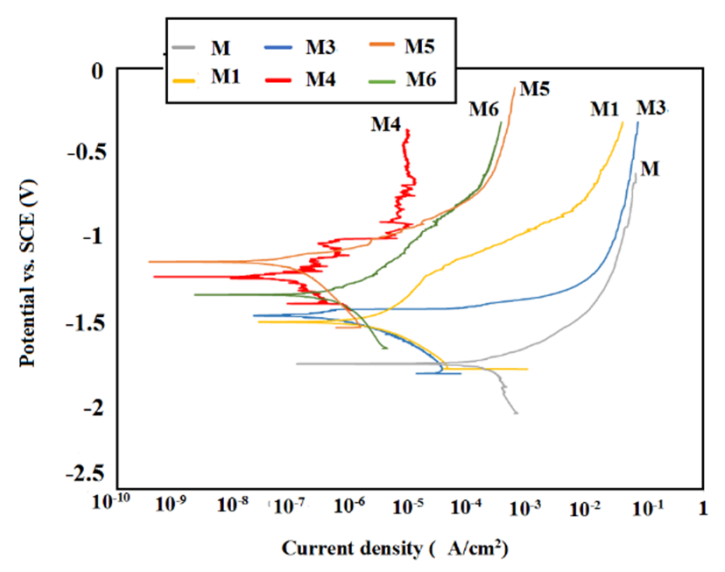

Figure 6. Polarization test of modified and unmodified samples (M, M1, M3-M6).

According to the EIS curves shown in Figure 7a (Nyquist) and Figure $7 \mathrm{~b}$ (Bode), the application of the $\mathrm{MAO}, \mathrm{MAO} /$ polymer, and $\mathrm{MAO} /$ nano-baghdadite/polymer coatings on the AZ91 substrate made dramatic changes in the corrosion resistance of this alloy. The Nyquist curve of the uncoated AZ91 sample showed a capacity quasi-loop (from high to moderate frequencies) and an inductive quasi-loop (at a low frequency), which can be attributed to the load transfer and the anion absorption/desorption process on the surface of the uncoated magnesium sample, respectively. The reason for observing the capacity loop from high to moderate frequencies in the AZ91 sample was the presence of an oxide layer, 
which could somewhat protect the metal from corrosion, although this oxide layer is not enough. Based on the EIS results for the coated specimens (Figure 7a), the MAO/polymer-coated specimen exhibited a better corrosion resistance behavior compared to the MAO-coated specimen; (i.e., it has a larger capacity loop diameter than the MAO-coated specimen). Addition of one percent baghdadite nanoparticles improved the corrosion behavior and caused a bigger capacity loop. Moreover, the single-loop Nyquist curve of the specimen containing $3 \mathrm{wt} \%$ baghdadite nanoparticles indicated that the electrolyte failed to pass through the $\mathrm{MAO} /$ polymer coating to reach the substrate. As a result, a better corrosion behavior was observed. Adding $5 \mathrm{wt} \%$ baghdadite to the polymer coating decreased the corrosion resistance (a decrease in the radius of the capacity loop) due to an increase in the roughness and defects in the coating. Figure $7 \mathrm{~b}$ shows the Bode curves of the coated and uncoated specimens. Also, Table 5 shows the magnitude of impedance for different specimens at low frequencies. As can be seen, the magnitude of impedance for the uncoated specimen, the MAO-coated specimen, and the specimen with a polymer coating containing $3 \mathrm{wt} \%$ baghdadite increased from 2100 to 4500 and $76000 \Omega \cdot \mathrm{cm}^{2}$ in the low frequency zone, respectively. According to the literature $[17,19]$, increasing the impedance in the lower frequency zone increases the corrosion resistance of the material.
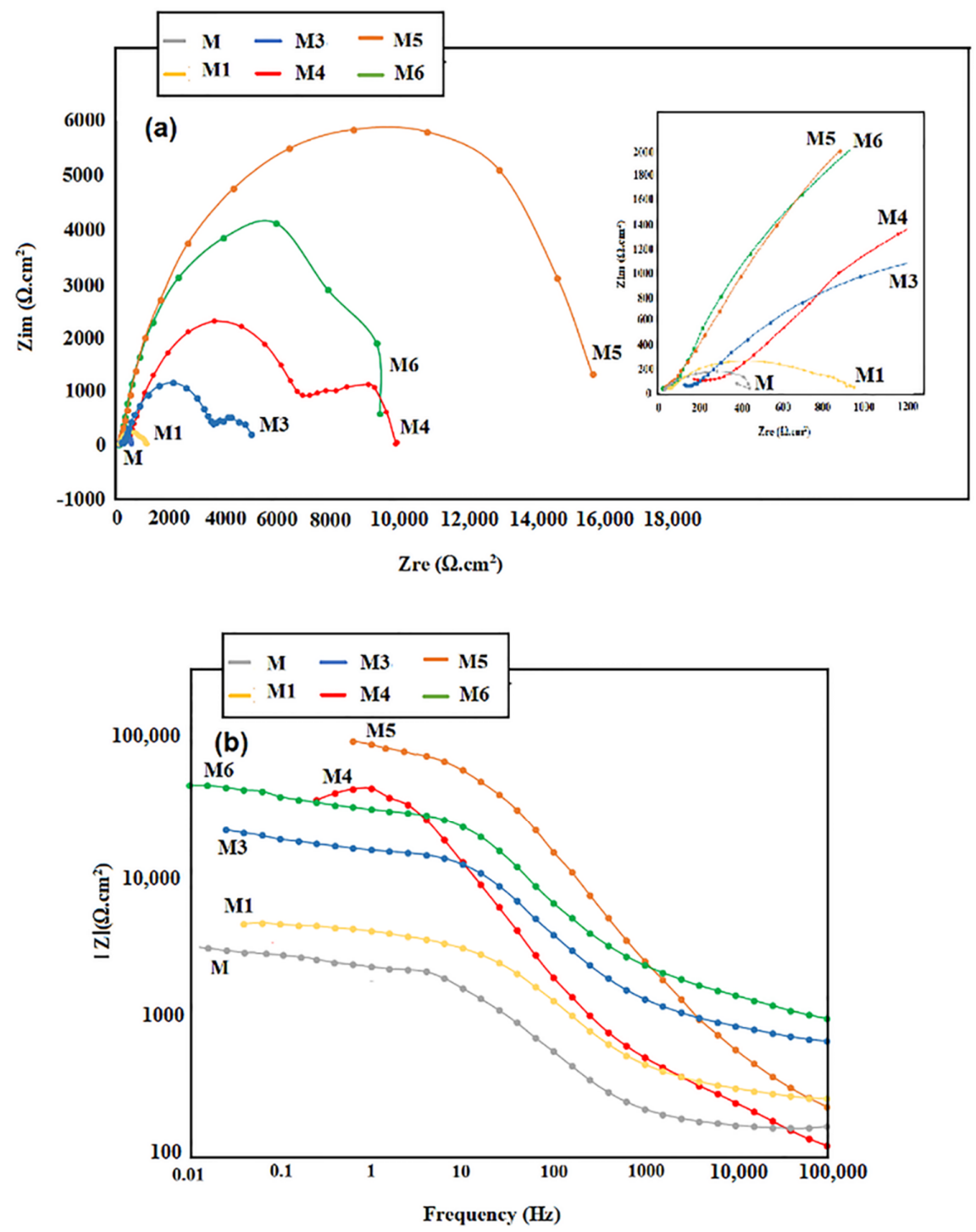

Figure 7. (a) Nyquist plots and (b) bode plots of unmodified and MAO-treated substrates in simulated body fluid (SBF). 
Table 5. The magnitudes of impedance for different specimens at low frequencies.

\begin{tabular}{cc}
\hline Samples & Impedance in Low Frequency $(\Omega)$ \\
\hline M & 2100 \\
M1 & 4500 \\
M3 & 20,000 \\
M4 & 41,000 \\
M5 & 76,000 \\
M6 & 45,000 \\
\hline
\end{tabular}

In order to further investigate the details of the EIS curves, equivalent electrical circuits simulated by Zview software version 3.4 were used for the uncoated specimen, the MAO-coated specimen, and the specimen with a ceramic/polymer composite coating (Figure 8 and Table 6 ). In these models, $R_{\mathrm{s}}, R_{\mathrm{a}}$, and $R_{\text {coat }}$ are the resistance of solution, the charge-transfer resistance, and the coating resistance, respectively. $C P E_{\mathrm{dl}}$ and $C P E_{\text {coat }}$ are constant phase elements corresponding to the double-layer capacitive behavior and the capacitive capacitance of the coating, respectively. As shown in Table 6, the total resistance of the specimens $\left(R_{\mathrm{t}}=R_{\mathrm{a}}+R_{\text {coat }}\right)$ increased as a result of applying the MAO/nano-baghdadite/polymer coating compared to those of the uncoated specimens and the specimens only coated with MAO. Showing a better capacitive behavior due to the application of this coating compared to that of the uncoated specimen was also proof of an improvement in the corrosion behavior. Among all the specimens, M5 exhibited the highest corrosion resistance, the lowest capacitive capacitance, and the lowest corrosion rate.

Table 6. Electrochemical impedance spectroscopy (EIS) parameters derived from equivalent electrical circuits simulated by Zview software for modified and unmodified sample.

\begin{tabular}{|c|c|c|c|c|c|c|c|c|}
\hline Samples & $R_{\mathrm{s}}$ & $R_{\mathrm{a}}$ & $R_{\text {coat }}$ & $R_{\mathrm{t}}$ & $C P E_{\text {coat }}$ & $n_{1}$ & $C P E_{\mathrm{dl}}$ & $n_{2}$ \\
\hline$M$ & 159.5 & 1648 (related to substrate) & - & 1648 & - & - & $2.3055 \times 10^{-5}$ & 0.921 \\
\hline M1 & 258 & 224.3 & 4223 & 4447.3 & $9.9148 \times 10^{-6}$ & 0.8726 & $3.5678 \times 10^{-6}$ & 0.761 \\
\hline M4 & 698 & 32851 & 1771 & 34,622 & $6.13424 \times 10^{-8}$ & 0.923 & $9.4792 \times 10^{-7}$ & 0.899 \\
\hline M5 & 110.6 & 81134 & 1991 & 83,125 & $8.1442 \times 10^{-8}$ & 0.833 & $2.1283 \times 10^{-7}$ & 0.932 \\
\hline M6 & 79.5 & 45592 & 1951 & 47,543 & $6.5313 \times 10^{-7}$ & 0.942 & $1.288 \times 10^{-6}$ & 0.894 \\
\hline
\end{tabular}
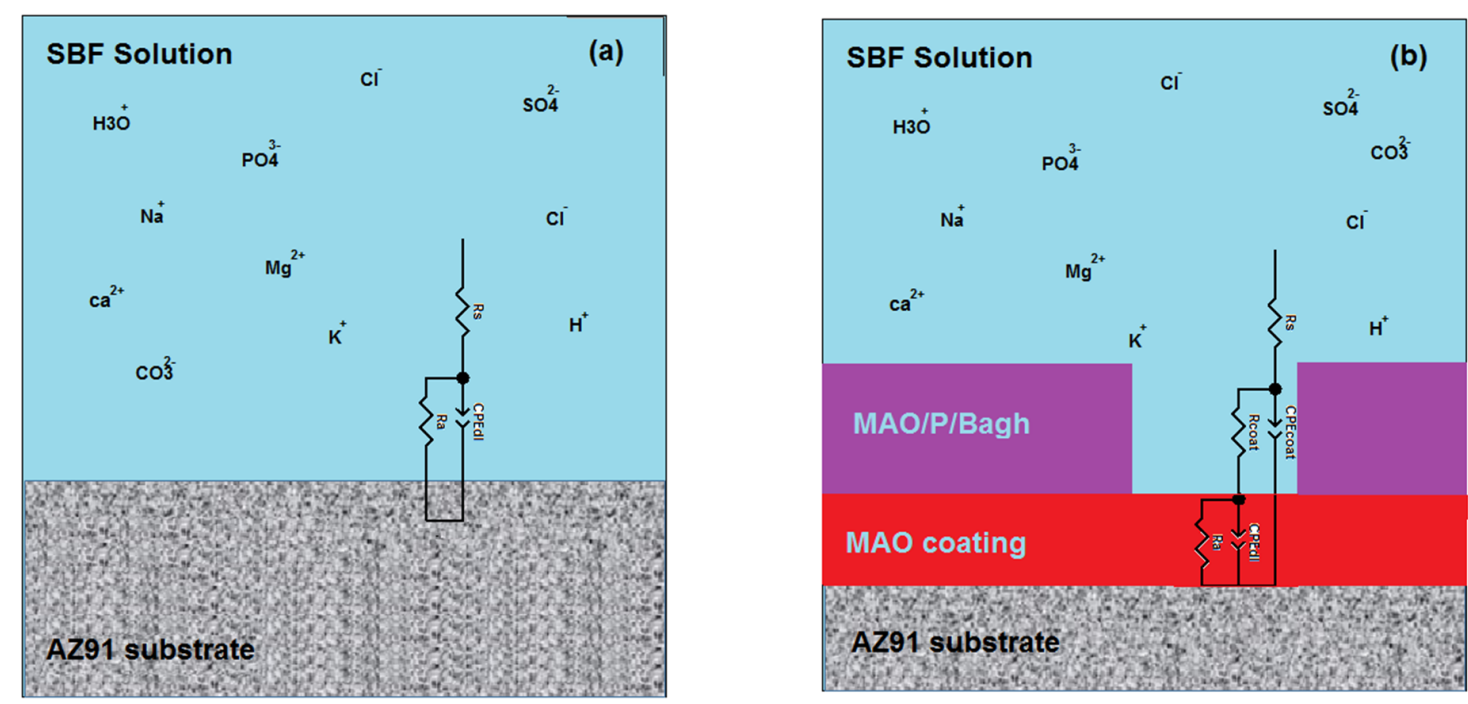

Figure 8. Equivalent electrical circuits simulated by Zview software for (a) unmodified and (b) modified samples.

Figure 9a-1 shows the SEM images of modified and unmodified specimens after corrosion in two different magnifications. As seen, the uncoated specimen (M) was affected by pitting corrosion on its 
entire surface. Higher magnifications revealed that corrosion products with spherical morphology exist inside the cavities. Based on the previous studies, corrosion of biodegradable magnesium alloys occurs in SBF solution containing $\mathrm{Cl}^{-}$ions according to the following reactions $[33,38]$ :

$$
\begin{gathered}
\mathrm{Mg} \rightarrow \mathrm{Mg}^{2+}+2 \mathrm{e}^{-} \\
\mathrm{Mg}^{2+}+2 \mathrm{OH}^{-} \rightarrow \mathrm{Mg}(\mathrm{OH})_{2} \\
\mathrm{Mg}(\mathrm{OH})_{2}+2 \mathrm{Cl}^{-} \rightarrow \mathrm{MgCl}_{2}+2 \mathrm{OH}^{-}
\end{gathered}
$$

Subsequently, after immersing the AZ91 alloy in the SBF solution, $\mathrm{Cl}^{-}$ions penetrated into the substrate, pitting corrosion occurred, and the corrosion product $\mathrm{Mg}(\mathrm{OH})_{2}$ was deposited on the surface. However, with applying the polymer coating on the surface, the number of cracks and cavities on the surface decreased, and as a result, the corrosion rate reduced [35]. In fact, coating acted as a protective layer between the substrate and the electrolyte. As can be seen in the SEM images of M1 and M3, pitting corrosion occurred; however, it was not observed in specimens with ceramic/polymer coating. Only some cracks can be seen in some parts of the coating after $1 \mathrm{~h}$ of corrosion testing. In these specimens, the calcium, silicon, and zirconium ions in the surface of coating were combined with the phosphate group in the electrolyte to produce calcium-phosphate compounds, which was deposited on the surface and improved the corrosion resistance [33]. Furthermore, the formation of these compounds on the surface improved the bioactivity of samples. M5 exhibited the highest number of calcium-phosphate compounds on its surface, and as a result showed a higher corrosion resistance. The EDS results M5 (Figure 9n) showed that the white particles on the surface of this sample contained calcium and phosphor elements, which showed the apatite formation and bioactivity of these specimens. The obtained results were in a good agreement with those of polarization. The AZ91 alloy, coated with the $\mathrm{MAO} /$ nano-baghdadite/polymer composite, can be an appropriate candidate for medical implants; however, further bio-clinical studies are required.
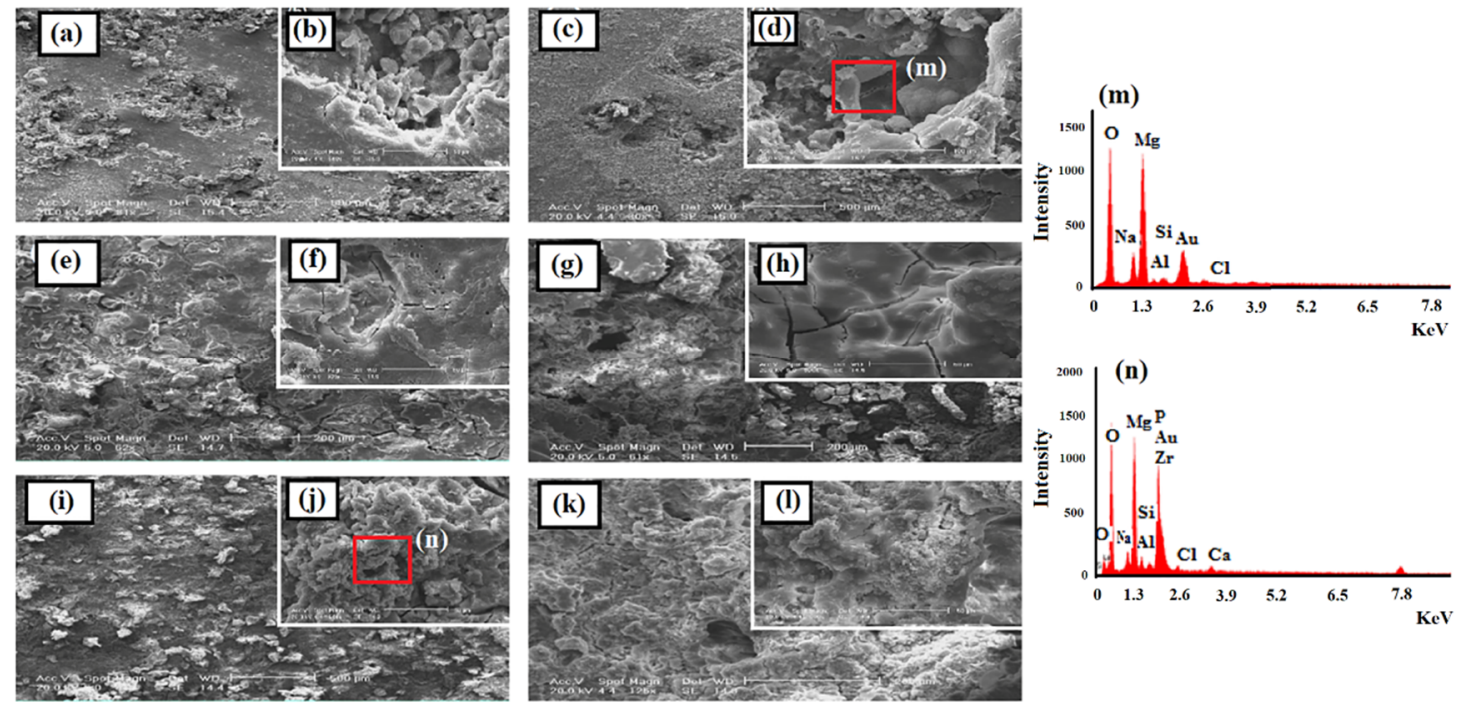

Figure 9. SEM micrograph of $(\mathbf{a}, \mathbf{b}) \mathrm{M},(\mathbf{c}, \mathbf{d}) \mathrm{M1},(\mathbf{e}, \mathbf{f}) \mathrm{M} 3,(\mathbf{g}, \mathbf{h}) \mathrm{M} 4,(\mathbf{i}, \mathbf{j}) \mathrm{M} 5,(\mathbf{k}, \mathbf{l})$ M6 in various magnification and EDS result of (m) M1 and (n) M5.

\section{Conclusions}

In this study, a nanocomposite coating made of PCL/Ch with different percentages of baghdadite was successfully applied to an anodized AZ91 alloy through an economical immersion method. The microstructure evaluation of the applied ceramic/polymer coatings showed the formation of a dense coating without any cracks and porosities on the AZ91 substrate, which improved corrosion 
resistance and decreased corrosion rate of this alloy. The results showed that the coating containing $3 \mathrm{wt} \%$ baghdadite exhibited the best corrosion resistance, the most appropriate roughness, and the lowest corrosion rate. Furthermore, adding baghdadite nanoparticles prevented pitting corrosion in the coating, and instead of the formation of unstable magnesium hydroxide in the medium containing $\mathrm{Cl}^{-}$, for these specimens, the corrosion products changed into calcium-phosphate compounds, which were more stable and improved the corrosion resistance of the coating.

Author Contributions: Investigation, F.S. and S.S.; methodology, F.S. and S.S.; project administration, R.E. and F.T.; resources, R.E. and F.T.; supervision, R.E. and F.T.; writing-original draft, F.S. and S.S.; writing-review and editing, R.E. and F.T.

Funding: This research received no external funding.

Conflicts of Interest: The authors declare no conflict of interest.

\section{References}

1. Saini, M.; Singh, Y.; Arora, P.; Arora, V.; Jain, K. Implant biomaterials: A comprehensive review. World J. Clin. Cases 2015, 3, 52. [CrossRef] [PubMed]

2. Katti, K.S. Biomaterials in total joint replacement. Colloids Surf. B Biointerfaces 2004, 39, 133-142. [CrossRef] [PubMed]

3. Oldani, C.; Dominguez, A. Titanium as a Biomaterial for Implants. Recent Adv. Arthroplast. 2012, 218, 149-162.

4. Sing, S.L.; Yeong, W.Y.; Wiria, F.E. Selective laser melting of titanium alloy with $50 \mathrm{wt} \%$ tantalum: Microstructure and mechanical properties. J. Alloy. Compd. 2016, 660, 461-470. [CrossRef]

5. Zhao, X.; Niinomi, M.; Nakai, M.; Hieda, J. Beta type Ti-Mo alloys with changeable Young's modulus for spinal fixation applications. Acta Biomater. 2012, 8, 1990-1997. [CrossRef] [PubMed]

6. Sadeghzade, S.; Emadi, R.; Tavangarian, F.; Naderi, M. Fabrication and evaluation of silica-based ceramic scaffolds for hard tissue engineering applications. Mater. Sci. Eng. C 2017, 71, 431-438. [CrossRef]

7. Leda, H. Engineering Materials for Biomedical Applications, 1st ed.; World Scientific: Toh Tuck Link, Singapore, 2004.

8. Johnson, J. Iliac crest autogenous bone grafting: donor site complications. J. South. Orthop. Assoc. 2000, 9, 91-97.

9. Staiger, M.P.; Pietak, A.M.; Huadmai, J.; Dias, G. Magnesium and its alloys as orthopedic biomaterials: A review. Biomaterials 2006, 27, 1728-1734. [CrossRef]

10. Zreiqat, H.; Howlett, C.R.; Zannettino, A.; Evans, P.; Schulze-Tanzil, G.; Knabe, C.; Shakibaei, M. Mechanisms of magnesium-stimulated adhesion of osteoblastic cells to commonly used orthopaedic implants. J. Biomed. Mater. Res. 2002, 62, 175-184. [CrossRef]

11. Song, G.-L. Corrosion Prevention of Magnesium Alloys, 1st ed.; Woodhead Publishing: Oxford, UK, 2013.

12. Diba, M.; Goudouri, O.-M.; Tapia, F.; Boccaccini, A.R. Magnesium-containing bioactive polycrystalline silicate-based ceramics and glass-ceramics for biomedical applications. Curr. Opin. Solid State Mater. Sci. 2014, 18, 147-167. [CrossRef]

13. Chen, Y.; Xu, Z.; Smith, C.; Sankar, J. Recent advances on the development of magnesium alloys for biodegradable implants. Acta Biomater. 2014, 10, 4561-4573. [CrossRef] [PubMed]

14. Najeeb, S.; Khurshid, Z.; Matinlinna, J.P.; Siddiqui, F.; Nassani, M.Z.; Baroudi, K. Nanomodified peek dental implants: Bioactive composites and surface modification-A review. Int. J. Dent. 2015, 2015, 381759. [CrossRef] [PubMed]

15. Wong, H.M.; Yeung, K.W.K.; Lam, K.O.; Tam, V.; Chu, P.K.; Luk, K.D.K.; Cheung, K.M.C. A biodegradable polymer-based coating to control the performance of magnesium alloy orthopaedic implants. Biomaterials 2010, 31, 2084-2096. [CrossRef] [PubMed]

16. Arifvianto, B.; Zhou, J. Fabrication of metallic biomedical scaffolds with the space holder method: A review. Materials 2014, 7, 3588-3622. [CrossRef] [PubMed]

17. Razavi, M.; Fathi, M.; Savabi, O.; Razavi, S.M.; Beni, B.H.; Vashaee, D.; Tayebi, L. Controlling the degradation rate of bioactive magnesium implants by electrophoretic deposition of akermanite coating. Ceram. Int. 2014, 40, 3865-3872. [CrossRef]

18. Guo, H.F.; An, M.Z.; Huo, H.B.; Xu, S.; Wu, L.J. Microstructure characteristic of ceramic coatings fabricated on magnesium alloys by micro-arc oxidation in alkaline silicate solutions. Appl. Surf. Sci. 2006, 252, 7911-7916. [CrossRef] 
19. Zhang, Y.; Yan, C. Development of anodic film on Mg alloy AZ91D. Surf. Coat. Technol. 2006, 201, 2381-2386. [CrossRef]

20. Gu, X.N.; Zheng, W.; Cheng, Y.; Zheng, Y.F. A study on alkaline heat treated Mg-Ca alloy for the control of the biocorrosion rate. Acta Biomater. 2009, 5, 2790-2799. [CrossRef]

21. Wu, C.; Wen, Z.; Dai, C.; Lu, Y.; Yang, F. Fabrication of calcium phosphate/chitosan coatings on AZ91D magnesium alloy with a novel method. Surf. Coat. Technol. 2010, 204, 3336-3347. [CrossRef]

22. Sadeghzade, S.; Emadi, R.; Soleimani, B.; Tavangarian, F. Two-Step modification process to improve mechanical properties and bioactivity of hydroxyfluorapatite scaffolds. Ceram. Int. 2018, 44, 19756-19763. [CrossRef]

23. Tiyyagura, H.R.; Fuchs-Godec, R.; Gorgieva, S.; Arthanari, S.; Mohan, M.K.; Kokol, V. Biomimetic gelatine coating for less-corrosive and surface bioactive Mg-9Al-1Zn alloys. J. Mater. Res. 2018, 33, 1449-1462. [CrossRef]

24. Wang, S.; Yaszemski, M.J.; Knight, A.M.; Gruetzmacher, J.A.; Windebank, A.J.; Lu, L. Photo-Crosslinked poly ( $\varepsilon$-caprolactone fumarate) networks for guided peripheral nerve regeneration: Material properties and preliminary biological evaluations. Acta Biomater. 2009, 5, 1531-1542. [CrossRef] [PubMed]

25. Jokar, M.; Darvishi, S.; Torkaman, R.; Kharaziha, M.; Karbasi, M. Corrosion and bioactivity evaluation of nanocomposite PCL-forsterite coating applied on 316L stainless steel. Surf. Coat. Technol. 2016, 307, 324-331. [CrossRef]

26. Sadeghzade, S.; Emadi, R.; Labbaf, S. Hardystonite-diopside nanocomposite scaffolds for bone tissue engineering applications. Mater. Chem. Phys. 2017, 202, 95-103. [CrossRef]

27. Sadeghzade, S.; Emadi, R.; Tavangarian, F. Combustion assisted synthesis of hardystonite nanopowder. Ceram. Int. 2016, 42, 14656-14660. [CrossRef]

28. Sadeghzade, S.; Emadi, R.; Tavangarian, F.; Doostmohammadi, A. The influence of polycaporolacton fumarate coating on mechanical properties and in vitro behavior of porous diopside-hardystonite nano-composite scaffold. J. Mech. Behav. Biomed. Mater. 2020, 101, 103445. [CrossRef]

29. Sadeghzade, S.; Emadi, R.; Ghomi, H. Mechanical alloying synthesis of forsterite-diopside nanocomposite powder for using in tissue engineering. Ceram. Silikáty 2015, 59, 1-5.

30. Sadeghzade, S.; Shamoradi, F.; Emadi, R.; Tavangarian, F. Fabrication and characterization of baghdadite nanostructured scaffolds by space holder method. J. Mech. Behav. Biomed. Mater. 2017, 68, 1-7. [CrossRef]

31. Sadeghzade, S.; Emadi, R.; Ahmadi, T.; Tavangarian, F. Synthesis, characterization and strengthening mechanism of modified and unmodified porous diopside/baghdadite scaffolds. Mater. Chem. Phys. 2019, 228, 89-97. [CrossRef]

32. Sadeghzade, S.; Emadi, R.; Tavangarian, F.; Doostmohammadi, A. In vitro evaluation of diopside/baghdadite bioceramic scaffolds modified by polycaprolactone fumarate polymer coating. Mater. Sci. Eng. C 2020, 106, 110176. [CrossRef]

33. Roohani-Esfahani, S.I.; Dunstan, C.R.; Davies, B.; Pearce, S.; Williams, R.; Zreiqat, H. Repairing a critical-sized bone defect with highly porous modified and unmodified baghdadite scaffolds. Acta Biomater. 2012, 8, 4162-4172. [CrossRef] [PubMed]

34. Pozzo, L.D.Y.; da Conceição, T.F.; Spinelli, A.; Scharnagl, N.; Pires, A.T.N. Chitosan coatings crosslinked with genipin for corrosion protection of AZ31 magnesium alloy sheets. Carbohydr. Polym. 2018, 181, 71-77. [CrossRef]

35. Sowmya, S.; Bumgardener, J.D.; Chennazhi, K.P.; Nair, S.V.; Jayakumar, R. Role of nanostructured biopolymers and bioceramics in enamel, dentin and periodontal tissue regeneration. Prog. Polym. Sci. 2013, 38, 1748-1772. [CrossRef]

36. Golshirazi, A.; Kharaziha, M.; Golozar, M.A. Polyethylenimine/kappa carrageenan: Micro-arc oxidation coating for passivation of magnesium alloy. Carbohydr. Polym. 2017, 167, 185-195. [CrossRef] [PubMed]

37. Razavi, M.; Fathi, M.; Savabi, O.; Vashaee, D.; Tayebi, L. In vitro study of nanostructured diopside coating on Mg alloy orthopedic implants. Mater. Sci. Eng. C 2014, 41, 168-177. [CrossRef]

38. Joughehdoust, S.; Behnamghader, A.; Imani, M.; Daliri, M.; Doulabi, A.H.; Jabbari, E. A novel foam-like silane modified alumina scaffold coated with nano-hydroxyapatite-poly ( $\varepsilon$-caprolactone fumarate) composite layer. Ceram. Int. 2013, 39, 209-218. [CrossRef] 
39. Nassif, N.; Ghayad, I. Corrosion protection and surface treatment of magnesium alloys used for orthopedic applications. Adv. Mater. Sci. Eng. 2013, 2013, 532896. [CrossRef]

40. Agarwal, S.; Curtin, J.; Duffy, B.; Jaiswal, S. Biodegradable magnesium alloys for orthopaedic applications: A review on corrosion, biocompatibility and surface modifications. Mater. Sci. Eng. C 2016, 68, $948-963$. [CrossRef] 